\title{
A non-prescription analgesic alleviated migraine headache pain and symptoms
}

\author{
Lipton RB, Stewart WF, Ryan RE, et al. Efficacy and safety of acetaminophen, aspirin, and caffeine in alleviating migraine \\ headache pain. Three double-blind, randomized, placebo-controlled trials. Arch Neurol 1998 Feb;55:210-7.
}

\section{Question}

In patients with a history of migraine headache, can a non-prescription combination product (Excedrin ExtraStrength that contains acetaminophen [paracetamol], aspirin, and caffeine) reduce migraine headache pain and symptoms?

\section{Design}

3 randomised, double blind, placebo controlled trials with data combined for presentation.

\section{Setting}

20 clinical centres in the US.

\section{Patients}

1357 patients (mean age 36.7 y, 79\% women) with a history of confirmed migraine headaches (International Headache Society criteria). Inclusion criteria were age $\geqslant 18$ years, good health, migraine headache frequency from 1 headache every 2 months to 6 each month, moderate headache pain without treatment, and vomiting $<20 \%$ of the episodes. $92 \%$ of patients used their assigned medication.

\section{Intervention}

677 patients were allocated to active medication (2 tablets of unbranded Excedrin Extra-Strength tablets, Bristol-Myers Squibb, that contained acetaminophen, $250 \mathrm{mg}$; aspirin, $250 \mathrm{mg}$; and caffeine, $65 \mathrm{mg}$ in each tablet) to treat pain from 1 acute self recorded migraine headache. 680 patients were allocated to placebo. Rescue medication could be taken after 2 hours.

\section{Main outcome measures}

Self reported pain intensity differences from baseline, proportion of patients with pain reduced to mild or none at 2 and 6 hours, symptoms, and functional ability. Secondary outcomes were the same measures at 1,3 , and 4 hours, and need for rescue medications.

\section{Main results}

Pooled analysis showed more patients in the active drug group had reduced pain $(\mathrm{p}<0.001)$ and no pain $(\mathrm{p}<0.001)$ than in the placebo group at 2 and 6 hours (table). More patients in the placebo group had used rescue medicine by 6 hours. All the symptoms that were assessed (pain, nausea, photophobia, phonophobia, and functional disability) were less frequent at 2 and 6 hours for patients in the active drug group $(p \leqslant 0.01$ for all comparisons). No serious adverse effects occurred in either group.

\begin{tabular}{|c|c|c|c|c|}
\hline \multicolumn{5}{|c|}{$\begin{array}{l}\text { Conclusion } \\
\text { A non-prescription combination product that included acetami- } \\
\text { nophen, aspirin, and caffeine alleviated migraine headache pain } \\
\text { and symptoms. } \\
\text { Acetaminophen, aspirin, and caffeine (active drugs) v placebo for migraine } \\
\text { headache }\end{array}$} \\
\hline Outcomes & Active drugs & Placebo & $R B I(95 \% C I)$ & $N N T(C I)$ \\
\hline $\begin{array}{l}\text { Reduced pain at } \\
2 \mathrm{~h}\end{array}$ & $59 \%$ & $33 \%$ & $\begin{array}{l}81 \% \\
\text { (59 to 106) }\end{array}$ & 4 \\
\hline $\begin{array}{l}\text { Reduced pain at } \\
6 \mathrm{~h}\end{array}$ & $79 \%$ & $52 \%$ & $\begin{array}{l}52 \% \\
(40 \text { to } 66)\end{array}$ & $\begin{array}{l}4 \\
(3 \text { to } 5)\end{array}$ \\
\hline No pain at $2 \mathrm{~h}$ & $21 \%$ & $7 \%$ & $\begin{array}{l}192 \% \\
\text { (111 to } 304)\end{array}$ & $\begin{array}{l}8 \\
(6 \text { to } 10)\end{array}$ \\
\hline No pain at $6 \mathrm{~h}$ & $51 \%$ & $24 \%$ & $\begin{array}{l}117 \% \\
\text { ( } 84 \text { to } 155)\end{array}$ & $\begin{array}{l}4 \\
(3 \text { to } 5)\end{array}$ \\
\hline $\begin{array}{l}\text { No rescue drugs } \\
\text { by } 6 \mathrm{~h}\end{array}$ & $88 \%$ & $73 \%$ & $\begin{array}{l}20 \% \\
\text { (14 to } 27)\end{array}$ & $\begin{array}{l}7 \\
\text { (5 to } 10)\end{array}$ \\
\hline
\end{tabular}

*Abbreviations defined in glossary; RBI, NNT, and CI calculated from data in article.

Source of funding: Bristol-Meyers Squibb Co, New York, NY.

For correspondence: $\operatorname{Dr} R$ B Lipton, Department of Neurology, Montefiore Medical Center, 111 East 210th Street, Bromx, NY 10467, USA. Fax +1 3013211044.

A modified version of this abstract appears in ACP Journal Club 1998 Sept-Oct and Evidence-Based Medicine 1988 Sept-Oct.

\section{Commentary}

Most patients with migraine use nonprescription medications that have not undergone adequate clinical investigation. Lipton et al used high quality, high power, clinical trials to investigate a 20 year old popular remedy and produced important results for patients with migraine and for clinicians. The design methodology, using a placebo control, is appropriate to determine the efficacy of this intervention. The trials confirmed for the first time that a single dose nonprescription drug combination was effective in the treatment of single episode uncomplicated migraine headache and associated symptoms. This efficacy was reflected in the relatively few patients who required the use of a rescue medication by 6 hours: $12 \%$ of the patients taking the drug combination compared with $27 \%$ taking the placebo. This study excluded the $25-35 \%$ of patients with migraine who were usually severely incapacitated during their attack and the indeterminate number of people who develop rebound headache that is often attributed to the overenthusiastic use of non-prescription drugs that contain caffeine. ${ }^{12}$ No indication of the efficacy of this treatment was shown for another large group of patients with migraine-women with hormonal imbalances. Caution is also needed for patients who are sensitive to any of the individual drugs contained in this preparation (acetaminophen, aspirin, and caffeine) and in similar non-prescription drug combination products.

It is tempting to suggest that in the absence of similar combination products
1 tablet of aspirin, 1 of acetaminophen, and a cup of strong coffee may be just as effective. In practice, many patients with uncomplicated single episode migraine who use a single dose strategy for self medication should benefit from this effective and safe combination product.

Gordon Gadsby, RGN, RMN, PhD Course Leader in Pain Management School of Health and Community Studies De Montfort University

Leicester, UK

1 Mannix LK, Frame JR, Solomon GD. Alcohol, smoking, and caffeine use among headache patients. Headache 1997;37:572-6.

2 Moore KL, Noble SL. Drug treatment of migraine: part I. Acute therapy and drugrebound headache. Am Fam Physician 1997;56: 2039-48. 